\title{
Material Gains: The FY '87 Federal Budget
}

President Reagan is requesting increases for materials research in the FY 1987 budget proposal he sent to Congress on February 5 . That budget request includes a number of new starts for research facilities-among them some of those most highly sought by the National Research Council's Major Materials Facilities Committee. The budget proposal also includes several new initiatives that would place greater emphasis within the funding agencies on materials-related issues-like processing and ceramics.

Overall, the budget would increase federal spending on research and development for all science and engineering disciplines by $16 \%$-or almost $\$ 9$ billion - to $\$ 60.8$ billion. However, these increases are not spread proportionately across the disciplines or funding agencies. For example, while the Department of Defense (DOD) now conducts roughly $65 \%$ of all federal $R \& D$, it's slated to receive $95 \%$ of the FY' $87 R \& D$ increases. The requested $74 \%$ rise to $\$ 4.8$ billion for the Strategic Defense Initiative (SDI), or "Star Wars" program, alone accounts for $23 \%$ of the total R\&D increase proposed for all agencies combined.

While DOD's weapons-research programs rely heavily on advances in materials $R \& D$, these development programs would not account for all of the materials gains. Even the National Science Foundation (NSF), which funds half of the federally supported basic materials science at universities, is slated to receive substantial increases.

To comply with the Balanced Budget and Emergency Deficit Control Act-better known for its Senate authors, Gramm, Rudman and Hollings-massive parings of the ' 87 budget are being anticipated. So it's anybody's guess how many of the proposals in the President's request will be accepted by the Congress. In a preface to his FY' 87 budget request, however, the President said: "High priority programs should be adequately funded." And where those priority programs were also deemed crucial to the national interest, he recommends that they even be expanded-"despite the very tight fiscal environment."

\section{Department of Defense}

That's one reason materials research is so highly valued by DOD. In his February 12 testimony before the House Armed Services Committee, Robert C. Duncan, director of the Defense Advanced Research Projects Agency (DARPA) led off his statement on the $F Y$ ' 87 budget by focusing on materials.

He said "breakthroughs in materials research will be of fering low cost ceramics and ceramic composites to defense applica- tions in armor, ceramic gun barrels, gas turbine engines and radar absorbing structures." He pointed to new coating materials that are expected to extend the range of carbon-carbon components in high-temperature gas-turbine engines, and low-temperature materials (with zero coefficient of thermal expansion at temperatures from -160 to $-250^{\circ} \mathrm{F}$ ) that are expected to provide options for new space structures. DAR$P A$ 's electronic-materials research is yielding a new permeable-base transistor that can operate at frequencies in excess of 100 gigahertz, with what he noted may be "the fastest switching speed of any transistor yet fabricated-on the order of a few picoseconds."

Overall, DARPA is requesting a budget increase of $\$ 97.9$ million-which would represent a real growth of $8.8 \%$ above the level appropriated for FY'86. (That does not reflect the roughly $10 \% \mathrm{Gramm-}$ Rudman-Hollings reduction for 1986 that went in to effect on March 1.) Much of the increase being sought for DARPA would be spent on two new initiatives-the hypersonic-velocity National Aerospace Plane and work on armor/anti-armor. Both programs are dependent on advances in materials research, Duncan said.

DARPA is requesting an FY' 87 increase for materials research of $\$ 5.1$ million-or $17.3 \%$. Duncan noted that much of the growth in this area is attributable to the agency's research into low-cost ceramics and ceramic composites, and to its Electronic Sciences Project (where work centers on research in to superlattices, molecular-beam epitaxy, and metal-organic chemical-vapor deposition).

Among highlights of DARPA's exploratory-development program is a Dual Alloy Radial Turbine, a novel gas-turbine testbed that will ultimately allow testing of advanced composite materials and structures at temperatures to $3,500^{\circ} \mathrm{F}$ and at pressure ratios of 25:1. Among other materialsdependent programs are its X-29 Advanced Technology Demonstrator (an aircraft to test advanced aerody namics, structures and flight controls); the Rotor System Research Aircraft due to fly for the first time later this year (with 56-foot diameter rotors fabricated of graphite composites); and Amber. a lightweight unmanned vehicle (fabricated from advanced composites) with sail-plane aerodynamics.

\section{Energy Department}

The administration is proposing to decrease its $R \& D$ budget for energy conservation by $58.3 \%$, fossil-fuel programs by $56.2 \%$, solar and renewable-energy research by $47.1 \%$, fission programs by $11.8 \%$ and fusion studies by $8.9 \%$. Because materials studies are a basic component of any energy-engineering discipline today, this might suggest that all materials programs within the Department of Energy (DOE) would suffer substantially under the President's plan. But according to Louis C. Ianniello, the basic materials research program that he directs within DOE, "is being treated as a high priority program." Its proposed FY'87 budget of $\$ 196.3$ million sports a $\$ 7.8$ million increase (after the March $1 \mathrm{Gramm-Rudman-Hollings} \mathrm{reduc-}$ tions) and several new materials initiatives.

One of those is a $\$ 17.5$ million experimental hall at the Los Alamos (National Laboratory) Spallation Neutron Source. Spallation neutrons are those that fly off a target hit with protons. Ianniello says that when it's completed, this experimental hall will have 15 beam lines supporting perhaps 300 users annually. Its high-energy neutron flux $-10^{16}$ neutrons per square centimeter per second-"will be the best in the U.S. and competitive with anything else in the world," he adds. First year funding for the three-year project is $\$ 5$ million.

The President is also requesting $\$ 1.5 \mathrm{mil}$ lion to begin design of a major new light source at Lawrence Berkeley Laboratory (LBL). Expected to cost $\$ 100$ million and take four years to construct, this facility would circulate 1-2 GeV electrons to produce synchrotron radiation in the ultraviolet to soft-x-ray range. The advanced facility is to be built around "insertion devices"-magnetic devices that wiggle the beam as it goes through to help tailor the radiation, to increase beam flux and to reduce beam spread.

DOE's materials science program would also allocate $\$ 3$ million to equip and operate a new, $6 \mathrm{GeV}$ light source at Argonne National Laboratory, and $\$ 2.5$ million for a new steady-state neutron-source research reactor at Oak Ridge National Laboratory (for use in neutron scattering studies). It would also provide funds to complete construction of the National Synchrotron Light Source upgrade at Brookhaven National Laboratory, and the Stanford (University) Synchrotron Radiation Laboratory enhancement.

Support would also continue for construction of the Center for Advanced Materials buildings at LBL. The Center's research will be aimed at materials "of interest to industry," Ianniello says. Already getting under way is work on polymer processing, ceramic-metal interfaces, catalysis, surface instrumentation, advanced semiconductor materials and light alloys.

\section{National Bureau of Standards}

Though the President has asked to cut Continued 
Continued from previous page

FY' 87 funding and staff for the Commerce Department's National Bureau of Standards (NBS), in Gaithersburg, MD, the Bureau's materials $R \& D$ programs are actually slated to increase. For example, its Institute for Materials Science and Engineering would increase $8 \%$ (after the March 1, Gramm-Rudman-Hollings cut), to $\$ 22.8$ million. Within that institute, funding would climb $4.7 \%$ for materials characterization, $4.5 \%$ for metallurgy and metals processing, and $13.6 \%$ for polymer and ceramic sciences. The latter increase represents the administration's attempt to garner the full $\$ 3$ million per year for NBS's ceramics initiative, begun last year.

Spurring the ceramics initiative is a recognition that Japan now controls $50 \%$ of the current $\$ 4.3$ billion world market in advanced ceramics. Kyoto Ceramics alone controls more than $60 \%$ of the market for ceramic integrated circuit packages, the Commerce Department says, and Toshiba plans to commercialize ceramic diesels in the late 1980 s and ceramic gas turbines in the 1990s.

The major technical barrier impeding commercialization of U.S. products is an inability to produce components reliably (owing to the sensitivity of ceramics to small defects in troduced in processing or in operation) and reproducibly (because of the inability to characterize adequately the starting powders, the processing factors that control their consolidation into a ceramic, and other performance limiting mechanisms). If the U.S. could become competitive in this field, however, the engine market alone could be worth $\$ 279$ billion to the U.S. over 20 years and create 250,000 new jobs, according to Commerce statistics.

But the highest priority initiative being requested for NBS in FY' 87 is a $\$ 27$ million cold-neutron source facility to be built over the next four years. The administration is asking $\$ 10$ million for the first year. NBS, in the process of modifying its research reactor, expects to have its cold (slow) neutron source operational by the end of the year. The new facility would make it possible to add 13 more state-of-the-art research stations, greatly increasing the number of U.S. researchers who could use its high flux of cold neutrons.

\section{National Science Foundation}

National Science Foundation (NSF) funding of basic research in to materials science would climb $7 \%$, or $\$ 7.7$ million, if the President gets his way. (The increase does not reflect the $4.3 \%$ FY' 86 Gramm-RudmanHollings reductions that went into effect for this agency on March 1.) Within this division, most areas-like solid-state chemistry, metallurgy, polymers, and ceramics and electronics materials-would climb a respectable $4-5 \%$. The $\$ 8.5$ million condensed-matter theory program would climb more than double that $-11.4 \%$. And the Materials Research Groups would soar a whopping \$4 million-or $83.3 \%$

The Materials Research Groups (MRG) program "promises to play a key role in advancing the field," according to Lewis Nosinow, director of NSF's materials research division. The first three-year awards under this program-averaging more than $\$ 1$ million each-were made to five university programs last August 15. Though the MRG program, encouraging cooperative research across disciplines, is only in its second year, the agency believes all "indications are that the most appropriate level of support is considerably higher than that currently available. The requested increase of $\$ 4$ million is a significant step toward the level needed and will support five to seven new MRG efforts."

Two big decreases are planned for this division, however. The agency plans to save $\$ 1.3$ million by phasing out two materials research laboratories-"in order to concentrate limited resources in fewer laboratories to strengthen them." In addition, the agency has decided to reduce by $\$ 800,000$ its support of the Wisconsin Synchrotron Radiation Center.

For NSF's engineering-science directorate, the President's budget again proposes big materials gains. Within the chemical, biochemical, and thermal engieering division, for example, programs on process and reaction engineering, and on kinetics and catalysis would both climb $7.7 \%$. Within the division on mechanics, structures and materials engineering, tribology (the science of friction, lubrication and wear) would climb $7.5 \%$, fluid dynamics and hydraulics would increase $9.5 \%$ and materials engineering and processing would jump $51.5 \%$.

Moreover, NSF will be launching a new initiative within both the materials research and engineering divisions on processing- research into the techniques that permit an increase in the scale of production while preserving the microstructural details that give a material its desired properties. Explains Nosinow, "dozens of industries see processing research as central to their future." That is why he believes "processing is right at the forefront of basic-engineering research."

\section{Gramm-Rudman-Hollings}

At present, the greatest threat to budget increases-including those in materials research-is the Gramm-Rudman-Hollings (GRH) law. Passed December 12, the law requires that budget cuts-known as sequestrations-must be implemented whenever congressionally appropriated spending for a year would cause the federal deficit to exceed the amount allowed under the Act.

On February 7, a three-judge panel found a key provision of the law unconstitutionalone that has the Comptroller General, an officer of the Congress, determining for the President any year's mandated sequestration.

Though the ruling is being appealed to the Supreme Court, the first wave of GRH reductions went into effect on March 1. They require each agency, except DOD, to cut discretionary spending by $4.3 \%$. DOD must pare $4.9 \%$, though certain of its agencies, like DARPA, took cuts of roughly $10 \%$ so that the SDI/Star Wars program wouldn't have to take any.

Finally, according to the Office of Management and Budget, even if the GRH law is ruled unconstitutional as early as July, there's no provision in the law that requires sequestered money be returned to agency spending accounts.

JANET RALOFF

\section{ON-SITE SHORT COURSES conducted at you own facilities or a nearby site}

The best way to keep your staff on top of their fields is through an on-going program of continuing education. One of the most efficient, cost-effective methods is to bring experts to your geographical location so that they can teach the latest techniques, discuss the newest research, and talk to your staff about the actual problems that they face daily.

The economic savings of On-Site progams are considerable, both in terms of time and budget. There are no travel fees or hotel costs for your staff, and attendees lose minimal time from their work.

MRS On-Site courses will be adapted to the specific needs of the sponsoring organization and the management will have an opportunity to interact with the instructor to discuss the course emphasis. Written requests from organizations will be handled on a first-come, first-served basis. For further details of courses which are available, prices and other information, write or call:

Vivienne Harwood Mattox, Short Course Manager, Materials Research Society, 440 Live Oak Loop, Albuquerque, NM 87122 ; telephone (505) 294-9532 


\section{MATERIALS PREPARATION}

\section{FOR TEM SAMPLES AND FOR CRYSTALS}

\section{CUTTING DISCS}

with

MODEL 350

Abrasive Slurry Drill

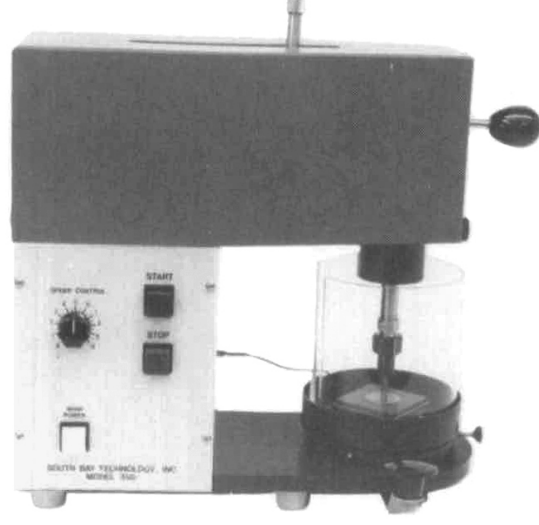

\section{THINNING}

with

MODEL 550C Jet Thinning Instrument
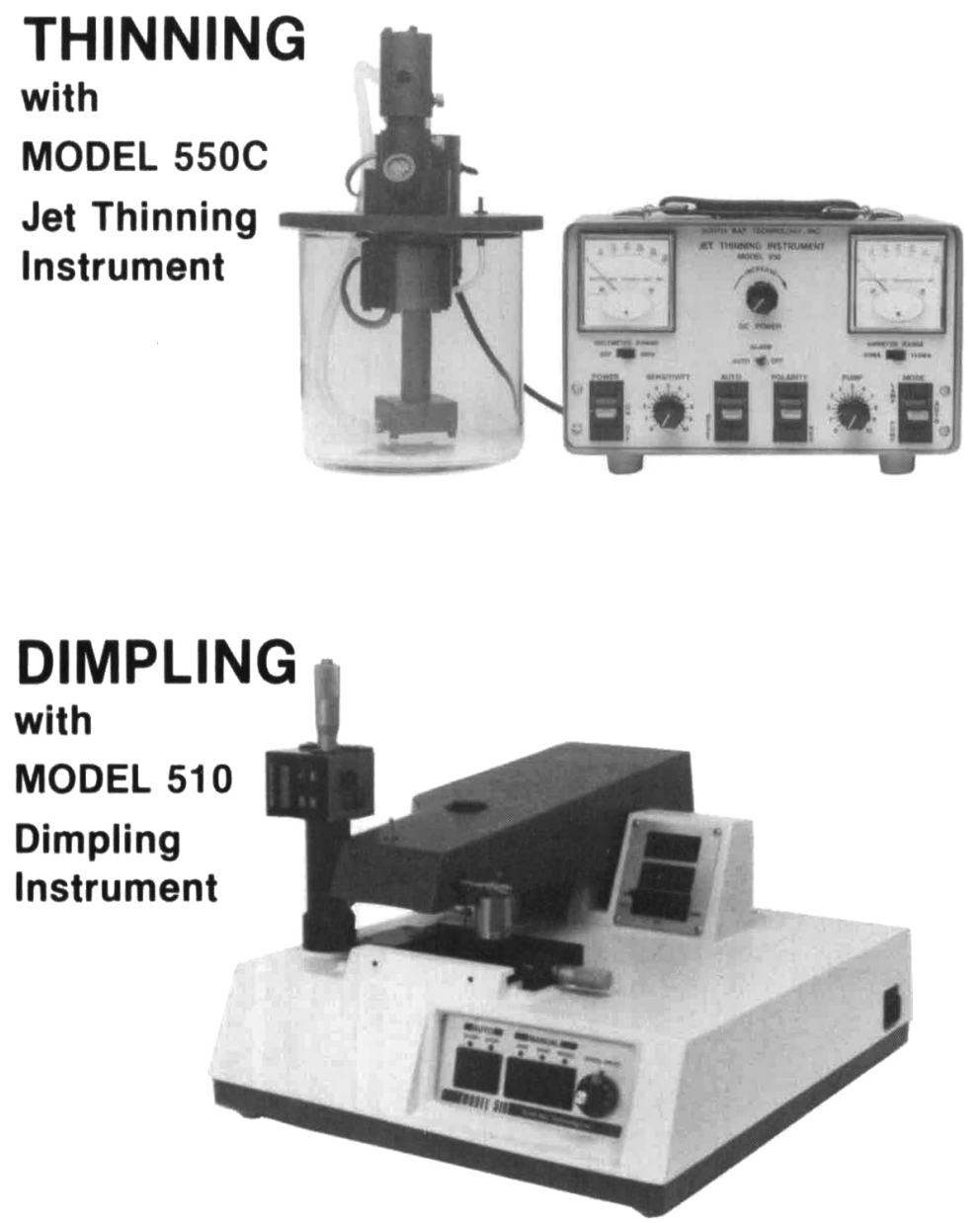

SLICING

with

MODEL 650

Low Speed

Diamond

Wheel Saw

AND OTHER DELICATE MATERIALS

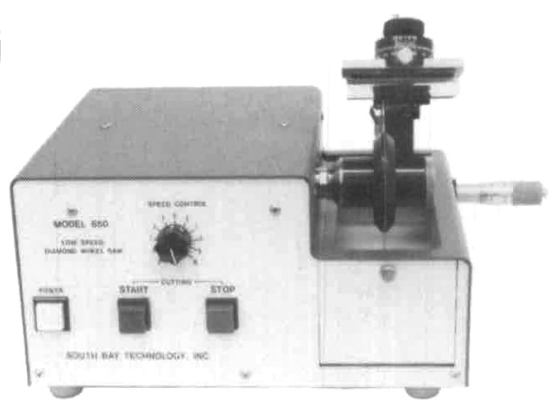

MODEL 850

Wire Saw

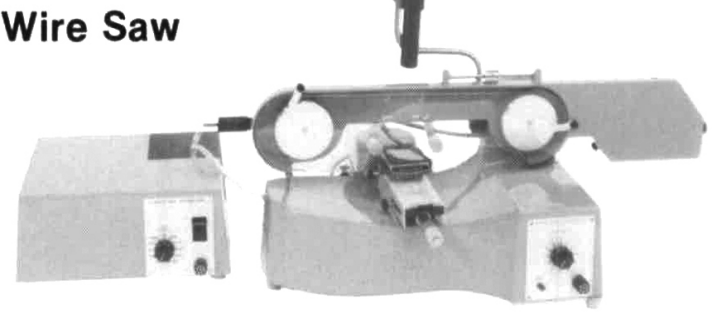

MODEL 750

Acid Saw

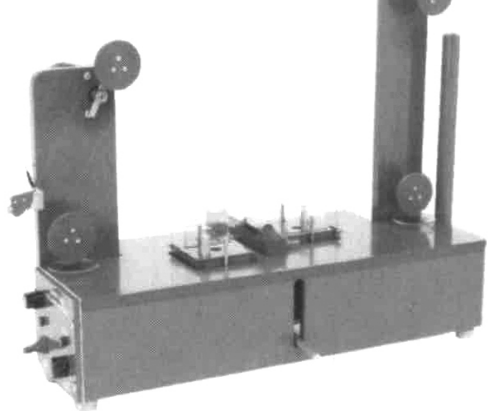

ORIENTATION with

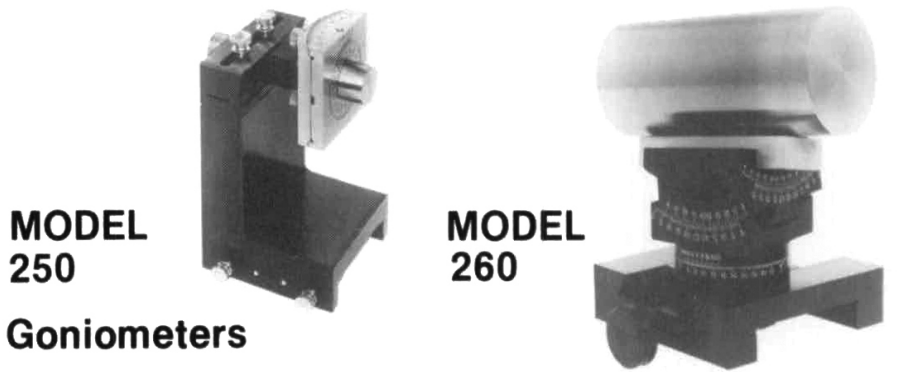

FOR INFORMATION ON THESE PRODUCTS AS WELL AS ON OUR HAND LAPPING FIXTURES AND ELECTROLYTIC CRYSTAL FACING INSTRUMENTS, CALL OR WRITE: 